\title{
Towards Experimental Handbooks in Catalysis
}

\author{
Annette Trunschke ${ }^{1}$. $\cdot$ Giulia Bellini $^{1} \cdot$ Maxime Boniface ${ }^{1}$. Spencer J. Carey ${ }^{1}$. Jinhu Dong ${ }^{1}$. Ezgi Erdem ${ }^{1,2}$.

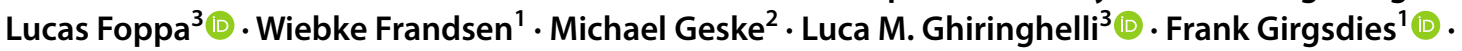 \\ Rania Hanna ${ }^{1}$. Maike Hashagen ${ }^{1}$. Michael Hävecker ${ }^{1,4}$. Gregory Huff ${ }^{1}$. Axel Knop-Gericke ${ }^{1,4}$. Gregor Koch ${ }^{1}$. \\ Peter Kraus ${ }^{1}$. Jutta Kröhnert ${ }^{1}$. Pierre Kube ${ }^{1}$. Stephen Lohr ${ }^{5}$. Thomas Lunkenbein ${ }^{1}$ (1) - Liudmyla Masliuk ${ }^{1}$. \\ Raoul Naumann d'Alnoncourt ${ }^{2}$ - Toyin Omojola ${ }^{1}$. Christoph Pratsch ${ }^{1}$. Sven Richter ${ }^{1}$. Christian Rohner ${ }^{1}$. \\ Frank Rosowski $^{5} \cdot$ Frederik Rüther $^{2} \cdot$ Matthias Scheffler $^{3} \cdot$ Robert Schlögl $^{1,4} \cdot$ Andrey Tarasov $^{1} \cdot$ Detre Teschner $^{1,4}(\mathbb{0}$. \\ Olaf Timpe $^{1} \cdot$ Philipp Trunschke $^{6} \cdot$ Yuanqing Wang $^{1,2} \odot \cdot$ Sabine Wrabetz $^{1}$
}

Accepted: 19 September 2020 / Published online: 6 October 2020

(c) The Author(s) 2020

\begin{abstract}
The "Seven Pillars" of oxidation catalysis proposed by Robert K. Grasselli represent an early example of phenomenological descriptors in the field of heterogeneous catalysis. Major advances in the theoretical description of catalytic reactions have been achieved in recent years and new catalysts are predicted today by using computational methods. To tackle the immense complexity of high-performance systems in reactions where selectivity is a major issue, analysis of scientific data by artificial intelligence and data science provides new opportunities for achieving improved understanding. Modern data analytics require data of highest quality and sufficient diversity. Existing data, however, frequently do not comply with these constraints. Therefore, new concepts of data generation and management are needed. Herein we present a basic approach in defining best practice procedures of measuring consistent data sets in heterogeneous catalysis using "handbooks". Selective oxidation of short-chain alkanes over mixed metal oxide catalysts was selected as an example.
\end{abstract}

Keywords Standard operation procedure $\cdot$ Best practice $\cdot$ Rigorous protocols $\cdot$ Descriptor $\cdot$ Data science $\cdot$ Machine learning · Artificial intelligence

\section{Introduction}

The application of catalyst technologies in the chemical industry stands for efficient and sustainable production of chemicals and fuels. Catalytic processes contribute to the minimization of waste formation and energy consumption, and are essential in terms of exhaust gas treatment not only

Electronic supplementary material The online version of this article (https://doi.org/10.1007/s11244-020-01380-2) contains supplementary material, which is available to authorized users.

Annette Trunschke

trunschke@fhi-berlin.mpg.de

1 Department of Inorganic Chemistry, Fritz-Haber-Institut der Max-Planck-Gesellschaft, Faradayweg 4-6, 14195 Berlin, Germany

2 UniCat-BASF Joint Lab, Technische Universität Berlin, Sekr. EW K 01, Hardenbergstraße 36, 10623 Berlin, Germany

3 The NOMAD Laboratory, Fritz-Haber-Institut der Max-Planck-Gesellschaft, Faradayweg 4-6, 14195 Berlin, Germany in the materials, but also in the energy and transport sectors

4 Max-Planck-Institut für Chemische Energiekonversion, Stiftstr. 34-36, 45470 Mülheim, Germany

5 BASF SE, Process Research and Chemical Engineering, Heterogeneous Catalysis, Carl-Bosch-Straße 38, 67056 Ludwigshafen, Germany

6 Institut für Mathematik, Technische Universität Berlin, Sekretariat MA 5-3, Straße des 17, Juni 136, 10623 Berlin, Germany 
[1]. More stable and effective catalysts are necessary to enable chemical energy conversion and storage at the required global scale. Only then is a closed carbon economy and the construction of sustainable energy systems possible [2].

As for production of basic chemicals and consumer products in the chemical industry, high selectivity to the desired reaction product allows for the efficient utilization of raw materials, the minimization of energy consumption by avoiding separation and purification steps, and the mitigation of waste formation or emission of greenhouse gases such as $\mathrm{CO}_{2}$. However, development of selective catalysts for reactions with numerous products, including selective oxidation of hydrocarbons [3-8], and synthesis of olefins and oxygenates via hydrogenation of carbon oxides [9-11], are challenging due to their underlying complex organic reaction networks.

The limited understanding of relations between catalyst structure and reactivity entails that technology changes are rare in the evolution of heterogeneous catalysis and attractive processes such as the direct synthesis of olefins or methanol from methane [7, 12], the selective oxidation of propane to oxygenates (acrolein or acrylic acid) [13, 14], or the synthesis of higher alcohols from synthesis gas [11], are commercially not yet implemented despite extensive research efforts.

Experimentally determined descriptors have been identified to guide catalyst developments in oxidation reactions $[15,16]$, acid-base reactions [17], or reactions on ceria catalysts [18], just to mention a few examples. Grasselli proposed "Seven Pillars in Oxidation Catalysis", which comprise lattice oxygen, metal-oxygen bond strength, host structure, redox properties, multifunctionality of active sites, site isolation, and phase cooperation, summarizing the seven most important features that should be taken into account in the design of metal oxides for selective oxidation of hydrocarbons [19].

Artificial intelligence may facilitate the identification of new, high-performance catalysts. Data science applications find renewed interest in heterogeneous catalysis research with the aim to discover selective catalysts for reactions that are influenced by a multitude of parameters, see for example references [20-32].

In the present essay we will explain our viewpoint why the use of artificial intelligence (AI) and data science requires a shift in the current paradigm of data generation and documentation in catalysis research. A definition of standards, rigorous measurement protocols, and best practice procedures that enables quality control and allows for the generation of suitable input data is necessary. Best practice and pitfalls in materials synthesis, kinetic measurements and characterization in both thermal catalysis and electrocatalysis or electrochemistry are permanent topics in the scientific literature [33-46] and in editorials [47-50]. Design issues, databases, and advanced characterization approaches are also discussed in materials science [51, 52]. Nonetheless, all efforts did not lead to any action across the catalysis community such as suggesting a minimum standard in the reporting of workflows and results. In other fields of science, such as crystallography, such structured reporting is now compulsory in each report [53]. Standards do not inhibit scientific creativity as they represent a minimum of experimentation metadata and results while setting no limits to additional work.

In this perspective we will explain why only a small portion of the catalysis-related data published in the past meets the minimum standards for data analysis even if only technically correct data were considered. The chemical dynamics of high-performance catalysts and the additional kinetic phenomena of activation and deactivation render information regarding catalyst history critical but unfortunately it is frequently not published. The widespread, simplified perceptions about the static nature of active sites seems to make such information an unnecessary detail that only adds redundant volume to scientific reports. We here propose the introduction of handbooks for all classes of reactions in which the minimum requirement to the investigation of a catalyst is prescribed as a binding directive for and a commitment of the community. We illustrate how such handbooks can be defined. Using a handbook would improve the significance and re-usability of the present data for future research. The standardized data could then be used, not only for the intended reaction, but also for studies with unforeseen contexts. AI technologies (including, e.g., machine learning, deep learning, and data mining) could accumulate the information of all groups participating in the study of a given reaction and enhance the level of insight that can be derived from the worldwide experimental effort.

In Chapter 2 we will discuss gaps between theory and experiment, which are related to the complexity and the dynamics of the systems investigated in heterogeneous catalysis and the frequently applied assumption that active sites are definite and fixed. We emphasize that the outcome of a catalytic measurement, i.e., the overall reaction rate (activity) or the ratio of various product formation rates (selectivity), strongly depends on how the measurement is performed. This differs from the determination of thermodynamic values (state functions), such as temperature, pressure, chemical potential, or reaction enthalpy. Random and systematic errors affect the measurements of thermodynamic and kinetic data likewise. However, experimentally determined kinetic values, such as a rate or an apparent activation energy, additionally depend on the workflow of the experiment and the "true" result cannot be extrapolated as will be outlined in Chapter 3. The resulting consequences for the conduction of experimental studies in heterogeneous catalysis are listed in Chapter 4. The oxidation of ethane, propane, and $n$-butane to olefins and oxygenates is chosen as example 
and a handbook for oxidation catalysis is proposed in Chapter 5. Conclusions and an outlook are provided in Chapter 6.

\section{Predictions and Restrictions}

Heterogeneous catalysis is a multi-dimensional phenomenon with respect to space and time (Fig. 1). Catalyst development involves not only the design of proper active sites embedded in a stabilizing active phase, but comprises the engineering of catalyst formulations for specific applications using binder and filling materials in the manufacture of catalyst pellets or electrodes. The macroscopic shape and the overall chemistry of the resulting composite as well as the catalyzed chemical reaction are linked to reactor technology and process conditions, i.e., the applied reactor technology depends on the specifics of the catalyst and the chemical reaction (rate, reaction network, involved phases, deactivation). Fluidized bed or fixed bed reactor technologies and lean or rich feed compositions, respectively, require different catalyst formulations. The composition of the composite, and the interaction between binder and active phase influence charge, mass, and heat transport properties, and may cause additional reactivity. To cope with all these interrelated phenomena in the development of high-performance catalysts, synthesis, shaping, testing, and materials characterization are implemented by applying iterative procedures involving numerous feedback loops in traditional catalysis research approaches [54]. Important target criteria are the predominant formation of the desired reaction product(s) at high reactant conversion in the catalytic reaction, long-term stability of the catalyst, or the availability of facile regeneration methods. Performance optimization, however, implies, in

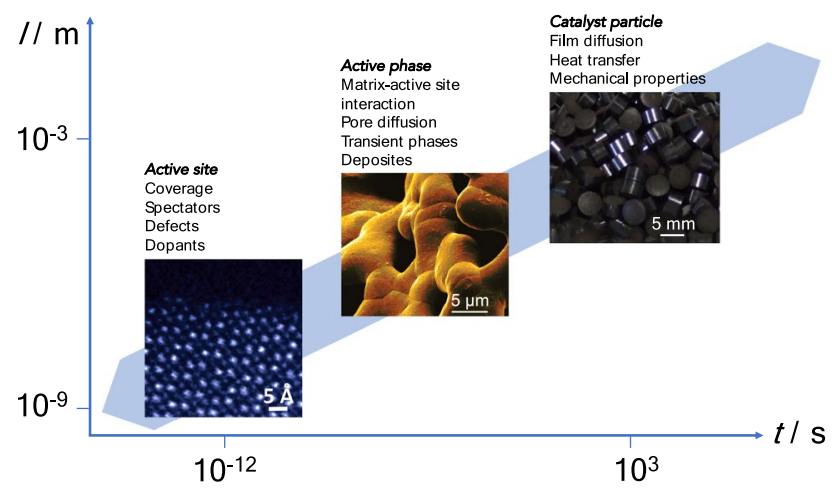

Fig. 1 Schematic illustration of time and length scale in heterogeneous catalytic systems that vary between $\mathrm{mm}$-sized catalyst particles and $\mathrm{nm}$-sized active sites, and minutes that the diffusion of a molecule from the gas phase through the pore system of the catalyst particle to the active site can take and picoseconds that elementary reactions last. Important parameters that influence the rate of a reaction in different dimensions are listed above the pictures most of cases, tremendous chemical and structural complexity of the technical catalyst, which complicates any detailed physical and chemical analysis. The limited insight into the mode of operation has the consequence that catalyst design based on atomic-scale understanding is extremely challenging as far as high performance catalysts are concerned.

The prediction of catalytic properties and the "design" of active phases require an overall and quantitative insight into the nature of the "active sites" and the knowledge of the complete reaction mechanism taking into consideration transport phenomena at all length scales and the catalyst formulation as well as any reactor technology aspects as discussed above. Integration of experiment and theory is necessary to achieve this goal since measurements of activity, selectivity, and stability carried out at the macro-scale in a laboratory reactor provide only indirect information. The underlying catalyst dynamics need to be taken into account.

Descriptors are frequently used to interpret trends in catalyst performance and to predict new catalysts. A descriptor is defined as a function of one or more parameters that project chemical-physical properties upon the library of observations. The descriptor represents exactly this function of parameters (primary features, e.g., the concentration of one element on the catalyst surface) that characterizes the phenomena pivotal to a certain material function (e.g. catalysis). The parameters entering in the descriptor function expression could be either measured by experiment or calculated from theory.

Predictive theory was developed that allows the forecast of general trends in reaction rates as a function of the composition of the active phase [55]. In simple cases, for example, in reactions that yield only one reaction product, i.e., where the catalyst exclusively determines the rate, whereas selectivity is no issue (e.g., CO oxidation over transition metals), descriptors were identified based on linear (Brønsted-Evans-Polanyi (BEP)) [56, 57] relationships (scaling relations) between calculated adsorption energies of species involved in the rate-determining step (thermodynamic value) and the reaction barrier (kinetic value) [58]. According to the Sabatier principle [59], activity maps that provide normalized, semi-quantitative links between surface bond energies of adsorbates and the rate of a catalytic reaction were implemented [60]. The adsorption and dissociation of diatomic molecules $\left(\mathrm{N}_{2}, \mathrm{NO}, \mathrm{CO}\right.$, and $\left.\mathrm{O}_{2}\right)$ on closed-packed and stepped transition metal surfaces were described by the $d$-band model [58]. The energetic position of the $d$-band center was identified as a descriptor that universally determines the strength of adsorption of diatomic molecules and, hence, the rate of conversion of these molecules in various reactions, including ammonia synthesis, NO reduction, methanation of $\mathrm{CO}$, and $\mathrm{CO}$ oxidation, in which the dissociation of the diatomic molecule represents the ratedetermining step. 
The reacting molecules in hydrocarbon oxidation are more complex. Numerous dehydrogenation, oxygen insertion, and $\mathrm{C}-\mathrm{C}$ bond splitting reaction pathways are possible, which generally result in the existence of complex reaction networks (Fig. 2), and the formation of product mixtures. The homolytic splitting of a $\mathrm{C}-\mathrm{H}$ bond in the first elementary surface reaction step is frequently assumed to be rate-limiting [61-64]. Hence, hydrogen affinity $E_{H}$ [62], which is defined as the difference between the formation energy of the reduced center $\left(\mathrm{M}_{\mathrm{m}} \mathrm{O}_{\mathrm{x}} \mathrm{H}_{\mathrm{y}+1}\right)$ and the formation energy of the fresh/ regenerated active site $\left(\mathrm{M}_{\mathrm{m}} \mathrm{O}_{\mathrm{x}} \mathrm{H}_{\mathrm{y}}\right)$, was introduced as universal descriptor for $\mathrm{C}-\mathrm{H}$ activation over different oxides, metals, and composite materials provided that the mechanism obeys a homolytic route [65]. Furthermore, assuming that lattice oxygen atoms located on the surface of a catalyst are the oxidizing agents in oxidation reactions over metal oxides [66], optimization of the oxygen vacancy formation energy $\Delta E_{V}$, for example by doping, was proposed to lead to

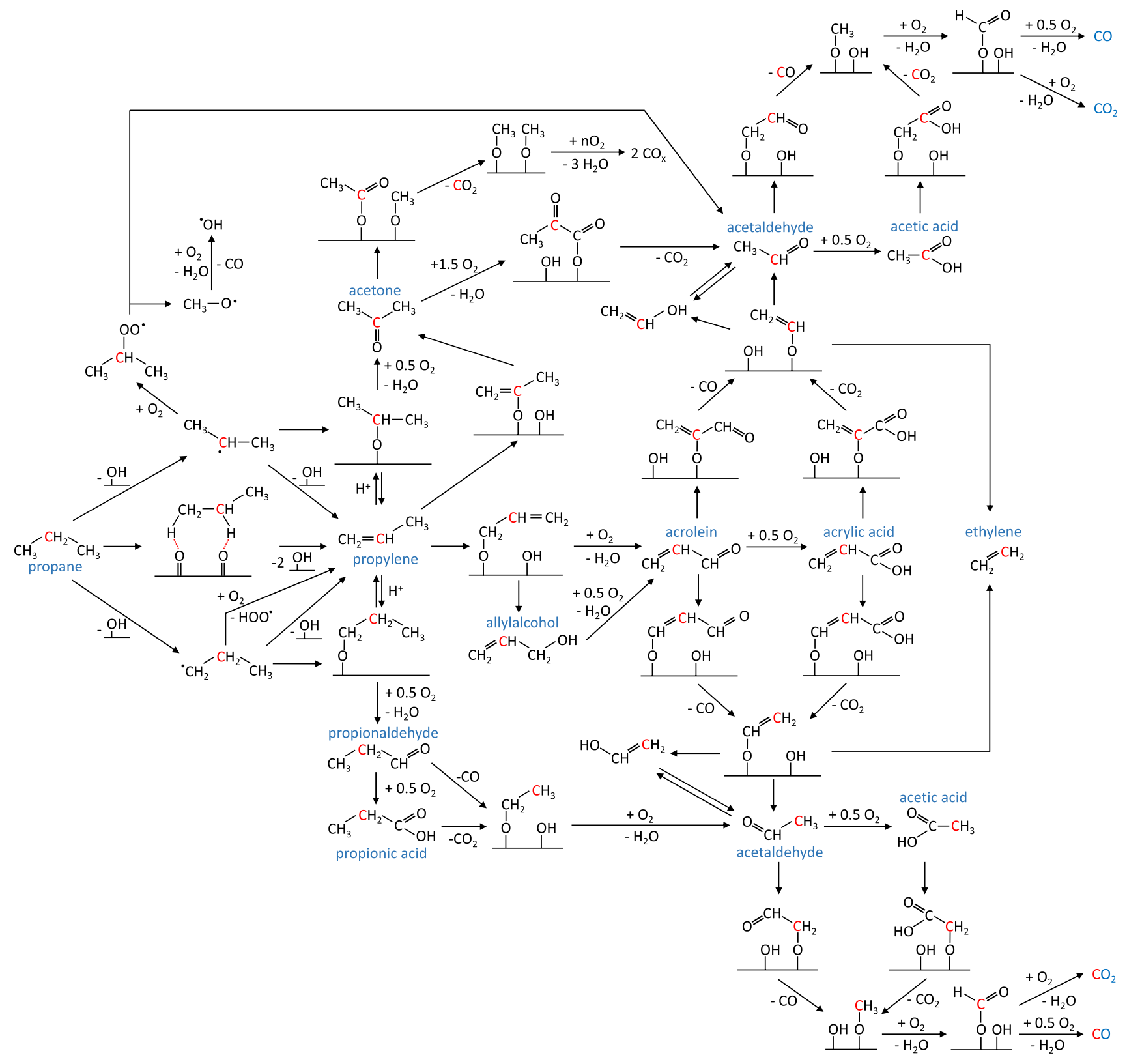

Fig. 2 Reaction networks of propane oxidation over Mo-V-based mixed metal oxide catalysts reprinted from [4] with permission of Wiley VCH. The reaction intermediates and products colored in blue were detected in the effluent gas stream by gas chromatography over a catalyst working in steady state 
a maximum in the reaction rate $[67,68]$. For good oxidation catalysts, $\Delta E_{V}$ needs to be small, but not too small to enable fast re-oxidation in agreement with the Sabatier principle. It was demonstrated that band gap, bulk formation energy, and electron affinity strongly influence the surface oxygen vacancy formation energy [69]. Such descriptors provide, however, only information about the overall rate of the reaction. Whether $\mathrm{C}-\mathrm{H}$ activation leads to the formation of a valuable oxidation product or to undesired formation of $\mathrm{CO}_{2}$, is not predicted.

Different types of lattice and adsorbed oxygen species are essential in oxidation reactions depending on whether the target molecule in, for example, alkane oxidation is an olefin produced by oxidative dehydrogenation, an oxygenate produced by selective oxidation, or $\mathrm{CO}_{2}$ produced by total combustion. Oxygen species with varying reactivity appear in the process of oxygen reduction on the surface of metal oxides under reaction conditions of a selective oxidation reaction. The intermediates include the polarized $\mathrm{O}_{2}$ molecule upon adsorption, differently charged molecular or atomic species with electrophilic character in the process of $\mathrm{O}_{2}$ dissociation, and nucleophilic $\mathrm{O}^{2-}$ ions after incorporation of oxygen into the oxide lattice. Control over occurrence and distribution of the various oxygen species on the surface of oxide catalysts under working conditions is the key issue in terms of selectivity [70-76]. BrønstedEvans-Polanyi relations, which are strongly coupled to the adsorbate geometry of diatomic molecules like oxygen in the transition state, were found from density functional theory for rutile-type metal oxides and perovskites [77]. Only in case of late transition states (with a geometry close to the final geometry of the dissociation products $2 \mathrm{O}^{*}$ ), the dissociative chemisorption energy was found to be as a descriptor for the dissociation of oxygen. In Solid Oxide Fuel Cells (SOFCs), the bulk oxygen $p$-band center or bulk vacancy formation energy were proposed to dictate the oxygen reduction reaction (ORR) rates over perovskites cathode catalysts [78]. Scaling relationships were established in the oxygen evolution reaction (OER) in electrochemical water oxidation between the binding energies of adsorbed (*) $\mathrm{HO}^{*}, \mathrm{HOO}^{*}$, and $\mathrm{O}^{*}$ species on oxide surfaces [79]. It appeared that the OER activity is depending on a larger number of physical and chemical properties [80], which required to construct multi-descriptor correlations [81]. An even more complex situation exists most likely under reaction conditions of alkane oxidation due to the concurrent presence of the hydrocarbon and carbon/oxygen-containing reaction intermediates on the surface of metal oxide catalysts (Fig. 2), which impedes the description by applying solely first-principles-based modelling [82]. The implications of complexity on the dynamic feedback loops between catalyst and reaction medium are discussed in the following chapter.

\section{Challenges and Opportunities}

Scaling relations are used to predict new active phase compositions or to encourage the implementation of desired catalyst nano-structures by application of specific synthesis techniques, which result in improved or thus so far unknown catalytically active materials. Descriptor-based approaches, however, generally concentrate on the active phase without taking into account the whole complexity of a catalyst system (Fig. 3) and largely rest upon assumptions concerning active site and reaction mechanism. Therefore, it is not unlikely that important leads for catalyst improvements and new materials will be missed.

Moreover, scaling relations are broken by the occurrence of strain [83-85], defects [86], ensemble effects [87], and intended (addition of promoters or additives) or incidental amounts of impurities in the catalyst [88]. These parameters are strongly influenced by catalyst synthesis and are reflected in the impact of morphology or surface composition on the performance of different catalysts with identical bulk structure [89]. The rate of a catalytic reaction is often governed by only a very small amount of highly active sites, so-called high-energy sites, generated, for example, by strain, executed by the interaction of the active site with its "non-innocent" support [84]. Active sites are formed as a result of frustrated phase transitions [90], and the underlying metastable phases are difficult to capture by models [91]. High-performance and structurally complex oxidation catalysts can terminate with numerous defects, which undergo changes during pretreatment and under reaction conditions (Fig. 3) [92, 93].

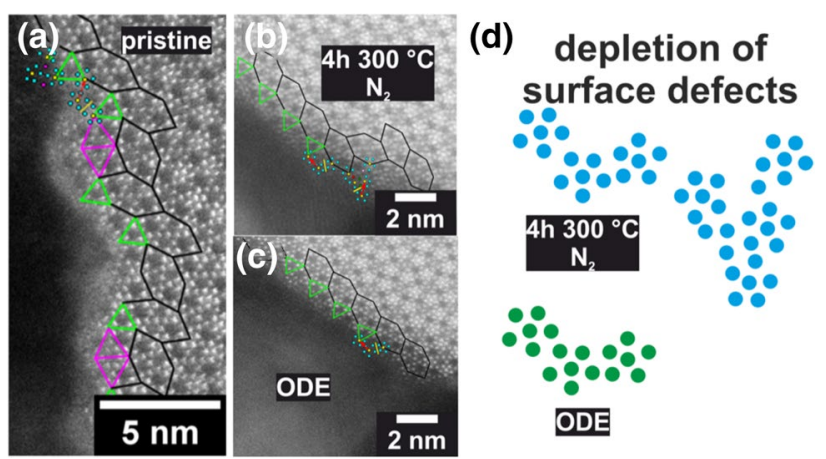

Fig. 3 Annular darkfield scanning transmission electron microscopy images of the defective surface of orthorhombic $(\mathrm{Mo}, \mathrm{V}) \mathrm{O}_{\mathrm{x}}$ (M1 phase) viewed along the crystallographic $c$-axis: a pristine sample, $\mathbf{b}$ after thermal treatment in $\mathrm{N}_{2}$ atmosphere at $300{ }^{\circ} \mathrm{C}$ for $4 \mathrm{~h}$, c image of the identical location after exposure to conditions relevant for the oxidative dehydrogenation of ethane (ODE), and $\mathbf{d}$ schematic illustration of the transformation of surface defects during reaction. Black hexagons-tiling of the ideal M1 phase, green and pink triangular motifs, yellow line-mirrored motif, red arrow-translated motif, red and pink circle-shared and rotated motif, respectively 
Such defects are generally not considered in models used to establish scaling relations.

In addition, the catalyst is changed in the course of the reaction due to transfer of electrons, protons, or other chemical processes, such as the dissolution of a reactant in the bulk of the catalyst. These dynamic changes may also have an impact on the rate of individual elementary steps and, therefore, on the reaction mechanism and the reaction barriers. Chemical changes of the catalyst might be reversible within one turnover, as generally assumed in the concept of a catalytic cycle. In such a case, reactivity can be controlled by understanding the electronic structure of the catalyst. Only under assumption of this boundary condition can the definition of a turnover frequency provide quantitative values that describe catalyst activity. However, irreversible changes are frequently observed and reflected in the well-known phenomena of catalyst activation or deactivation in the feed. Even if the bulk composition of the catalyst undergoes no changes the active and selective catalyst surface is generally only formed under steady-state operation [1]. The active site can also irreversibly deactivate in the course of just one catalytic turnover and new active sites are constantly generated due to solid state processes within bulk and/or surface of the catalyst under the influence of the feed, resulting in an overall constant number of active sites under steady-state conditions. Mars and van Krevelen proposed such a concept in oxidation catalysis [94]. Furthermore, a dynamic response of the electronic structure of the catalyst can occur in contact with the feed [95]. This can be measured by spectroscopic techniques and is, for example, reflected in the well-known observation of band bending that results in modification or control of charge transfer between the catalyst and the reactant(s) [96]. The catalyst dynamics can occur separately or in combination proving catalyst design and predictions exceptionally difficult.

In summary, catalysis is a kinetic phenomenon where all its results depend upon experimental conditions and no extrapolation between these conditions is possible. Its material science is characterized by a dynamic mutual response of catalyst and reaction medium modulated by transport phenomena at various length scales. Predictions are so difficult, due to the following analytical challenges:

- Complexity of both materials and reaction networks

- Detection limit for minor amounts of highly active species (dopants, defects, frustrated configurations)

- Challenge of time-resolution; generally, only the global reaction is experimentally observable, not the individual elementary steps

- Catalyst dynamics under operation conditions, i.e., the entanglement of solid state and surface chemistry of the catalyst and the chemistry in the gas or liquid phase
Consequently, descriptors that determine the catalytic properties will need to capture the complex and sometimes ill-understood interplay of several phenomena: reaction network, reaction conditions and catalyst dynamics. Such complexity was so far not taken into account when deriving reactivity descriptors. Instead, these descriptors were based on strong assumptions, for instance on the (static) catalyst active surface structure or rate-determining steps. As an alternative to the descriptors based on chemical intuition, we could take the opportunity to use the tools of artificial intelligence, which are currently undergoing renewed interest in heterogeneous catalysis [20-32], for descriptor identification based on data. In this case, the algorithm itself learns, from data, the possibly intricate correlation between a target property of interest and a set of potentially-relevant simpler materials properties offered by the user, the primary features. We thus hope to find a mathematical model that deepens our understanding of the relationship between the materials properties and the catalytic performance.

To capture this in a mathematical framework we define a vector of target properties $\boldsymbol{P}$, such as the formation rates of specific products, the selectivity, or the catalyst stability. We assume that the target properties $\boldsymbol{P}$ depend on a vector of physical properties $\boldsymbol{x}$ that can be easily determined experimentally. These properties may be, for instance, bulk and surface properties of the catalysts extracted from X-ray diffraction (e.g. unit cell volume) and X-ray photoelectron spectroscopy (e.g. surface elemental composition). The aim is to find a continuous function $\boldsymbol{P}$ that generalizes from a set of measurements $\left\{\left(P_{i}, \boldsymbol{x}_{i}\right): i=1, \ldots, n\right\}$ for $n$ catalysts to previously unknown compounds. In this sense, cross-validation can be used to assess the performance of the descriptors with a given data set. We want to find descriptors $\boldsymbol{d}=\boldsymbol{d}(\boldsymbol{x})$, which depend on the physical properties $\boldsymbol{x}$, and from which the target properties can be computed (i.e., $\boldsymbol{P}(\boldsymbol{x})=\boldsymbol{P}(\boldsymbol{d})$ ). The success of data-driven identification of descriptors for catalytic performance using artificial intelligence faces, however, at least two important challenges: data quantity and data quality.

Whereas traditional artificial-intelligence methods require large data sets for training, the number of data points that are typically available in catalysis, and, in general, in materials sciences, is rather reduced. This can be explained by the time and resource-consuming data generation. The sure independence screening and sparsifying operator (SISSO) approach is an artificial-intelligence method combining symbolic regression and compressed sensing for data-driven descriptor identification [97]. Contrary to standard AI methods, SISSO is efficient with rather reduced data sets. Furthermore, due to its symbolic-regression-based feature construction, it provides descriptors in the form of analytical expressions, from which the most relevant primary features for the property of interest are directly accessible. This is fundamental to gain 
physical insights on the underlying phenomena governing catalysis. When using SISSO, several catalyst properties can be offered as primary features and the algorithm itself selects those (and their combinations according to a set of mathematical operators-e.g. addition, subtraction, multiplication) that better describe the target property of interest.

Regarding data quality, a significant part of the research efforts to find descriptors for catalysis discussed previously is based on the use of quantities such as adsorption energies calculated by theory. Indeed, electronic-structure methods, and, in particular, density-functional-theory, have been successful in modeling bulk and surface material properties. However, the explicit modeling of heterogeneous catalysis (reaction rates, selectivity, etc.) at realistic reaction conditions remains to date only possible for particular cases under a significant number of approximations. Therefore, experimental data is of utmost importance for the identification of descriptors with predictive power. From the artificial intelligence standpoint, it is crucial that such experimental data is obtained in a consistent way and that it represents different scenarios. In particular, the artificial-intelligence method needs to be informed about good as well as bad catalysts. Extracting consistent and diverse data sets from available literature is a challenge, since every research work focuses on a specific experimental set-up and only success stories (good catalysts) are typically reported.

\section{Quality and Comparability of Kinetic Data}

The reaction kinetics in terms of a microkinetic model describe and predict the performance of a catalyst as function of the process conditions (i.e., temperature, pressure, catalyst mass, flow rate, and feed composition) in the idealized case that excludes any rate-modifying transport phenomena. Flowcharting this model requires detailed knowledge about the atomic structure of the active site(s) and every elementary step. In kinetic models the active (adsorption) site is indicated by the symbol *. According to the current paradigm, the active site structure changes in the course of one turnover (during one catalytic cycle), but * exists unaltered on the surface after the desorption of the product and is ready to perform the next cycle.

In the meso- and macroscopic scale of a continuous catalytic process the catalyst performance does not change with time when constant process conditions are applied. The heterogeneous catalyst operates in steady-state. But, even if a reaction is studied under steady-state conditions and the criteria for minimization of mass and heat transport limitations are fulfilled, the outcome of the catalytic testing is not necessarily defined and reproducible. This is due to well-known catalyst formation and conditioning processes that prevail during the pre-treatment and under operation conditions $[1,98]$. We refer to these processes as catalyst dynamics (Chapter 3) [1]. The catalyst undergoes chemical interactions with reacting molecules, additives, intermediates, and products. Bulk and surface chemistry of a freshly prepared solid catalyst adapt to the chemical potential of the environment under reaction conditions. The chemical potential is determined by the process conditions, but also by the catalytic reaction (conversion, product composition). The rate constants of the underlying processes differ. Solid state reactions occur usually slower compared to gas phase and surface reactions.

The active phase on the surface of $\mathrm{ZnO}$-supported $\mathrm{Pd}$ nanoparticles for example changes with time on stream in methanol steam reforming. It was observed that the catalytically active intermetallic compound PdZn is only created under reaction conditions [99]. The thickness of the surface alloy, and its resulting electronic structure determine the selectivity to $\mathrm{CO}$ or $\mathrm{CO}_{2}$, respectively. Another example is the selective hydrogenation of alkynes into alkenes over palladium catalysts [100]. Selectivity to alkenes requires a strong modification of the near-surface region of Pd by carbon, which is supplied by fragmented feed molecules. The formation of sub-surface carbides and hydrides is controlled by the feed composition, and thus, the population of subsurface sites of palladium by either hydrogen or carbon governs the selectivity to alkanes or alkenes, respectively. A third example is the industrial catalyst for oxidation of $n$-butane to maleic anhydride. Catalyst synthesis results in the precursor vanadyl hemihydrate, $\mathrm{VOHPO}_{4} \cdot 0.5 \mathrm{H}_{2} \mathrm{O}$, which is transformed into the active phase vanadyl pyrophosphate, (VO) ${ }_{2} \mathrm{P}_{2} \mathrm{O}_{7}$, by thermal procedures in reacting butane-oxygen mixtures [101]. These highly dynamic steps are important in delivering effective and stable catalyst performance over time periods of years and are referred to as catalyst conditioning [98]. The final steady-state activity and selectivity sensitively depend on the applied gas atmosphere, temperature program, duration and sequence of the steps [98]. Hence, the sequence of experimental steps in kinetic measurements (the workflow) is very important. In Fig. 4, a practical example for the dynamics of an oxidation catalyst is shown. Propane oxidation was performed according to different workflows over a mixed Mo-V-Te-Nb oxide catalyst, pretreated at $650{ }^{\circ} \mathrm{C}$ in argon for $2 \mathrm{~h}$ [102]. The selectivity to acrylic acid is shown as a function of propane conversion. The selectivity differs depending on whether the conversion was varied by changing the temperature and starting the experiment at low (blue data points) or high (purple data point) temperature. In this quick test, in which the temperature was increased starting from the freshly prepared and pretreated catalyst (blue data points), the catalyst appeared to have low selectivity to the desired product. Then, the catalyst was kept at $400{ }^{\circ} \mathrm{C}$ and the conversion was lowered by going stepwise to lower temperatures (purple data points). 


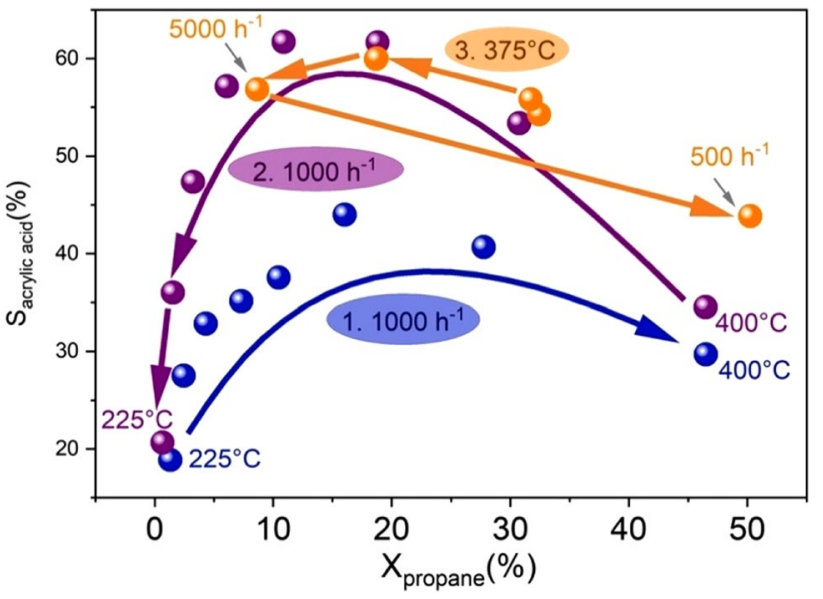

Fig. 4 Oxidation of propane over MoVTeNb M1 oxide performed according to different workflows as indicated by the colors and arrows; The selectivity to acrylic acid is shown as a function of propane conversion; All data was measured under steady-state conditions in a feed of $\mathrm{C}_{3} \mathrm{H}_{8} / \mathrm{O}_{2} / \mathrm{H}_{2} \mathrm{O} / \mathrm{He}=3 / 9 / 20 / 68 \mathrm{vol} \%$ and a gas hourly space velocity (GHSV) of $1000 \mathrm{~h}^{-1}$ in the experiments in which the temperature was varied: At first from 225 to $400{ }^{\circ} \mathrm{C}$ (up, blue data points) and secondly from 400 to $225^{\circ} \mathrm{C}$ (down, purple data points) in seven steps of $25 \mathrm{~K}$; After these two measurements, thirdly a GHSV variation $\left(500-5000 \mathrm{~h}^{-1}\right.$ ) was performed at $375{ }^{\circ} \mathrm{C}$ (orange data points)

The identical material now showed improved selectivity. The variation of conversion by changing the contact time at $375^{\circ} \mathrm{C}$ (orange data points), which finally was performed after measuring the purple data points, reproduced the purple curve. The selectivity improves further at the highest conversion, possibly due to the lower reaction temperature. The experiments show that the catalyst apparently adopts a different chemical state under the reaction conditions at high temperature and high propane conversion. The higher selectivity would not have been noticed when the catalytic test was stopped after reaching the highest reaction temperature (after completion of the blue curve). The example clearly illustrates that the experimental results of a catalytic test strongly depend on the workflow of the experiment. A clear link between the physical and chemical properties of the prepared and thermally pretreated $\mathrm{Mo}-\mathrm{V}-\mathrm{Te}-\mathrm{Nb}$ oxide catalyst and its performance in propane oxidation (Fig. 4) does not exist, because either $45 \%$ or $60 \%$ selectivity to acrylic acid were measured in steady-state under identical reaction conditions, i.e., at the reaction temperature of $350{ }^{\circ} \mathrm{C}$ and $20 \%$ propane conversion, respectively, depending on the previous history of the catalyst.

The majority of catalytic data reported in the literature were measured after short times on stream and at low conversion, which results, for example in case of oxidation reactions, in the desired high selectivity values of intermediates formed in the first step of consecutive reactions.
But it is not appropriate for exploring complex reaction networks that involve multiple steps and for the synthesis of oxygenates, which are often the product of several consecutive reactions. Frequently, information concerning the sequence of conditions in catalyst pretreatment and testing are only incompletely, if at all, reported. Whether intended or accidental, the procedures of catalyst synthesis are reluctantly described in many cases. Furthermore, the diversity of published data is limited, because negative results are rarely reported. Data quality in catalysis research is usually not verified against accepted standards.

In summary, due to these shortcomings and in particular in view of the catalyst dynamics described above, much data generated in kinetic investigations of catalysts are not suitable for analysis by data science techniques and artificial intelligence. Generation of experimental input must adequately support the requirements of artificial intelligence and re-usability of data by others.

In the following, we summarize 10 criteria, which need to be fulfilled prior to integration of experimental catalysis data into data sets used to predict new catalysts:

1. The synthesis and activation of a catalyst must be documented precisely and in such a way that reproduction in terms of bulk and surface structure as well as performance is possible without consultation with the original author.

2. The batch size must be large enough so that comprehensive characterization and catalytic testing is possible using the same batch; Generally, 15-20 g catalyst is needed.

3. Kinetic data must be linked to all metadata including the workflow of the entire experiment; Catalyst performance data must be documented together with the metadata completely and in a standardized form.

4. Catalysts need to be tested using a broad field of process parameters including temperature, pressure, contact time, and various feed compositions following standardized procedures since the optimal operation conditions depend very much on the catalyst and might vary significantly for various catalysts applied in the same reaction.

5. The experiments must be performed for sufficient long times on stream to verify either steady-state or catalyst deactivation/activation phenomena.

6. The absence of apparent transport limitations must be examined.

7. The catalytic experiment must be compared with respect to a standardized benchmark that is included in each measurement.

8. Physical and chemical standard characterization of the catalyst bulk and surface must be performed before and after use of the material in catalysis. 
9. Physical and chemical properties of catalysts, which will be directly correlated with functional data, must be measured under operation of the catalyst; in operando means simultaneous collection of spectroscopic and catalytic data in the same experiment.

10. Catalysis studies must report on successful and unsuccessful attempts likewise to ensure a sufficient diversity of the results.

In this respect, intra-community agreements appear beneficial within which catalytic tests are performed according to standard operation procedures defined in handbooks. In handbooks, the minimum requirement to the investigation of a catalyst is prescribed without putting restrictions on further experiments. The elaboration of a handbook for a specific reaction or class of reactions requires the input of the community and is an iterative process.

The practicability of a handbook has been explored in the present work using the example of alkane oxidation within the collaboration of two laboratories. This handbook will be presented in Chapter 5 and first hands-on experience will be reported.

\section{Implementation of Handbooks}

Immense amount of catalysis-related data is accumulated in the literature and in local laboratories to date. Information management and data analysis have, therefore, already a long history in catalysis research. Only a few examples will be mentioned briefly in the following.

Expert systems, which made empirical knowledge available, were developed and installed at the end of the last century. The systems were limited to specific reactions or topics, such as hydrogenation, oxidative dehydrogenation [103, 104], or kinetic analysis [105]. At the same time, efforts in terms of standardization have been undertaken. A group of European researchers decided to prepare a substantial batch of silica-supported platinum $\left(6.3 \% \mathrm{Pt} / \mathrm{SiO}_{2}\right.$ called EUROPT-1) to compare experimental procedures for catalyst characterization including chemical composition, total surface area, size distribution of Pt-containing particles, and chemisorption properties $\left(\mathrm{H}_{2}, \mathrm{CO}\right.$, and $\left.\mathrm{O}_{2}\right)$. The large-scale preparation was performed by industry (Johnson Matthey). The aim was that the catalyst will eventually acquire the status of a standard material, which will then be used by the academic and industrial catalysis community as a reference [106]. Recommendations for the selection of the experimental reactors and conditions have also been developed in chemical reaction kinetics $[33,35]$.

Around the turn of the century, high-throughput experimentation became a frequently applied method to screen for both new catalyst compositions and optimized reaction conditions [107-110]. To facilitate screening, library design by genetic algorithm (GA) was implemented [111, 112]. Decision trees and principal component analysis (PCA) were applied to extract large amount of data from the literature $[113,114]$ and from high-throughput experiments, in some cases ending up with catalyst compositions and reaction conditions already known from experience [112, 115]. Despite all efforts, no real breakthrough in the implementation of new technologies was achieved. Only a few catalyst systems with composition optimized by combinatorial screening or data since based on literature data [116], in particular for the production of pharmaceuticals [117], were transferred to industry. We argue that this was the case because the inherent complexity of high-performance catalysts, the necessary large process parameter space in catalyst testing, and the prevailing catalyst dynamics were not taken into account in these approaches [118].

In the future, a closer collaboration and the agreement upon certain standards within the catalysis community will be necessary to establish reliable links between experiment and theory as illustrated in Chapter 4 . This requires improved information management in the field and allow for open access to data generated not only in the researcher's respective laboratory. The general availability of catalysisrelated data according to the FAIR principle $[119,120]$ is to the benefit of all as we can collaborate and test new hypotheses by application of artificial intelligence using the data available globally much easier than today. FAIR data will have to be findable (F), accessible (A), interoperable (I), and re-usable (R), which requires improvements of existing and the installation of new data infrastructures [119].

Concerning data quality, this means that the data must be suitable to be interoperable with later and external analysis including other purposes, not only in the framework of the original scientific question. As outlined in Chapter 4, catalytic data must be well documented by metadata, and by the workflow of the experiment, including a detailed description of catalyst synthesis. The catalyst synthesis should be preferably performed in an automated manner. Furthermore, the machine-readable published description must be complete enough to allow a full reconstruction of the experiment. However, for this purpose, users need to share much more information than what is available in the today's literature including a much better formalized organization.

For these reasons, we propose the use of experimental handbooks in heterogeneous catalysis research (Fig. 5, Supporting Information). To develop standard experimental operation procedures and to evaluate the practicability of handbooks, a collaboration project between the Departments of Inorganic Chemistry and the NOMAD Laboratory of the Fritz-Haber-Institut der Max-Planck-Gesellschaft in Berlin, and the BasCat Joint Lab between BASF SE and the Technical University Berlin, Germany, was initiated. We selected 


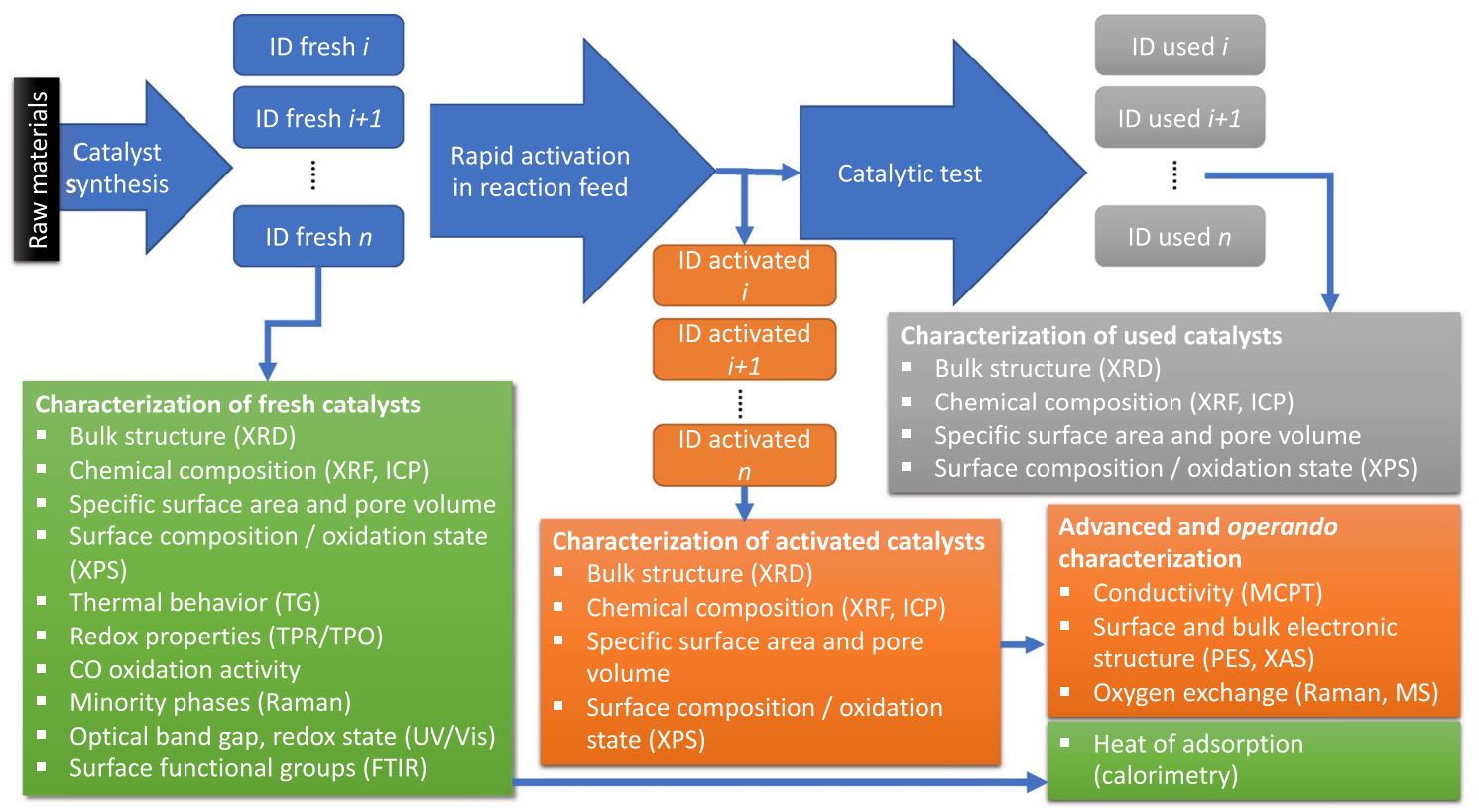

Fig. 5 Proposed workflow in the handbook "Data Science Project in Oxidation Catalysis", for details see Supporting Information

the direct oxidation of the short-chain alkanes ethane, propane and $n$-butane over complex mixed metal oxide catalysts as example for a challenging heterogeneous catalytic reaction. The current version of the handbook, which is continuously revised in the ongoing project, is attached in the Supporting Information. The workflow in the handbook is presented in Fig. 5.

Thirteen different catalysts (Fig. 6) were chosen based on their known diverse performance in the target reactions and synthesized according to well-defined procedures in batch sizes as indicated in the figure. The example of MoVTeNb oxide synthesis is presented in Fig. 7. Although some of the process steps were performed in automated laboratory reactors, such as the hydrothermal synthesis of MoVTeNb oxide [121, 122], for other steps, such as separation or drying, implementation of automation is not easy in an academic laboratory, which bears the risk of reproducibility issues.
Fig. 6 Schematic representation of the crystal structure of 13 oxidation catalysts synthesized and studied in the course of the development of a handbook in oxidation catalysis; The ID clearly indicates the synthesized batch; The mass of catalyst prepared is also given

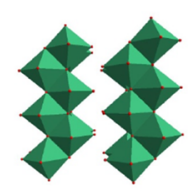

$\mathrm{MoO}_{3}$ (ID31013) $23.00 \mathrm{~g}$

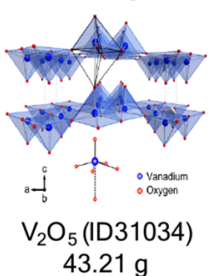

$43.21 \mathrm{~g}$

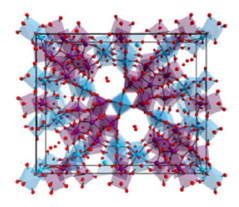

$\mathrm{MoVO}_{\mathrm{x}}(\mathrm{ID} 31012)$

$11.61 \mathrm{~g}$

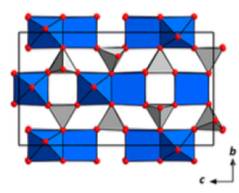

VPP (ID31650)

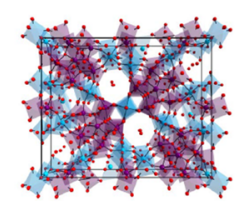

$\mathrm{MoVTeNbO}_{\mathrm{x}}(\mathrm{ID} 31652)$ $18.67 \mathrm{~g}$

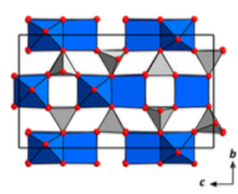

Amorphous VPP (ID3
$10.89 \mathrm{~g}$

VOPO ${ }_{4}{ }^{\star} 2 \mathrm{H}_{2} \mathrm{O}$ (ID31199) $\mathrm{V}_{0.167} \mathrm{~W}_{0.5} \mathrm{P}_{0.333} \mathrm{O}_{2.5+x}$ (ID31749)
$18.67 \mathrm{~g}$
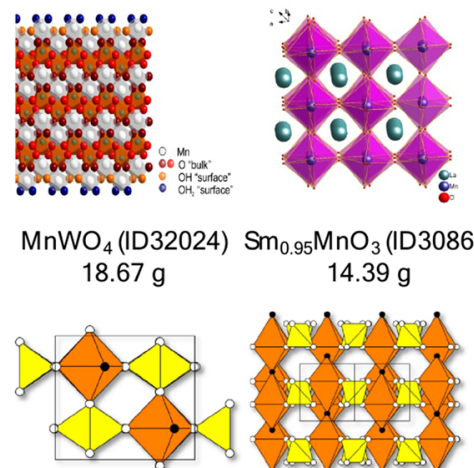

$\mathrm{nWO}_{4}$ (ID32024) $\mathrm{Sm}_{0.95} \mathrm{MnO}_{3}$ (ID30869)

$14.39 \mathrm{~g}$

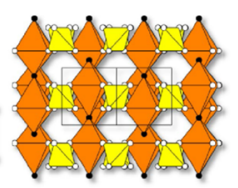

1) $\beta-\mathrm{VOPO}_{4}(\mathrm{ID} 31620) \quad \alpha_{11}-\mathrm{V}_{0.8} \mathrm{~W}_{0.2} \mathrm{OPO}_{4}$

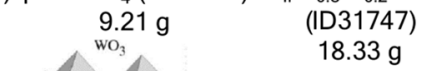

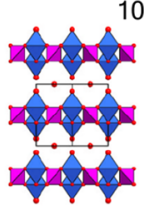

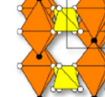

$\alpha_{\mathrm{II}}-\mathrm{VOPO}_{4}$ (ID31915)

$14.22 \mathrm{~g}$
$11.80 \mathrm{~g}$

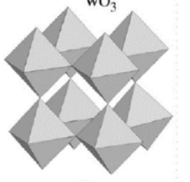

$13.86 \mathrm{~g}$ 


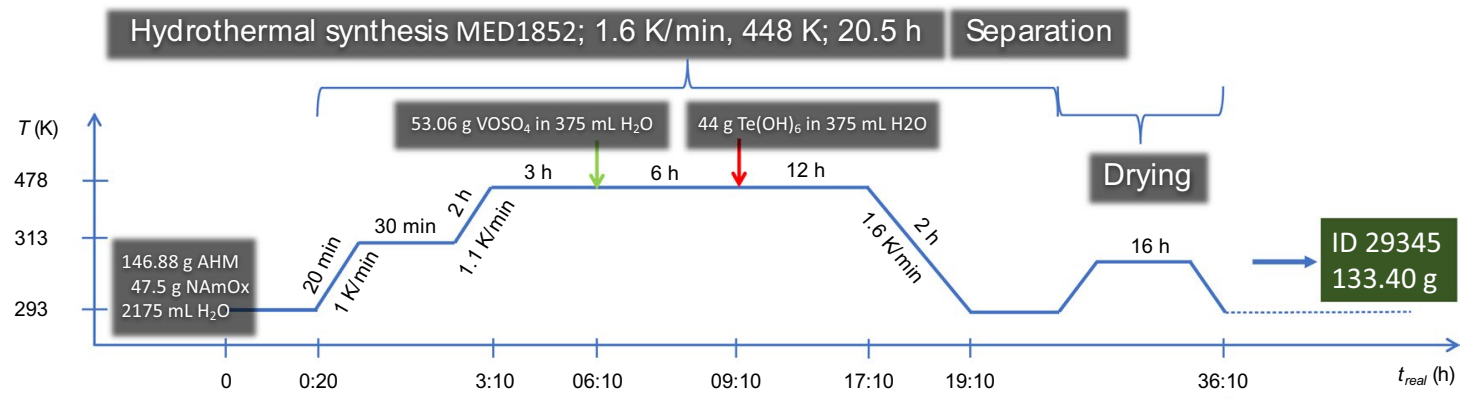

Activation in rotating furnace (UTP H): $20 \times 2 \mathrm{~g}, 10 \mathrm{~K} / \mathrm{min}, 923 \mathrm{~K}, 2 \mathrm{~h}, \mathrm{Ar}(100 \mathrm{~mL} / \mathrm{min}$ )

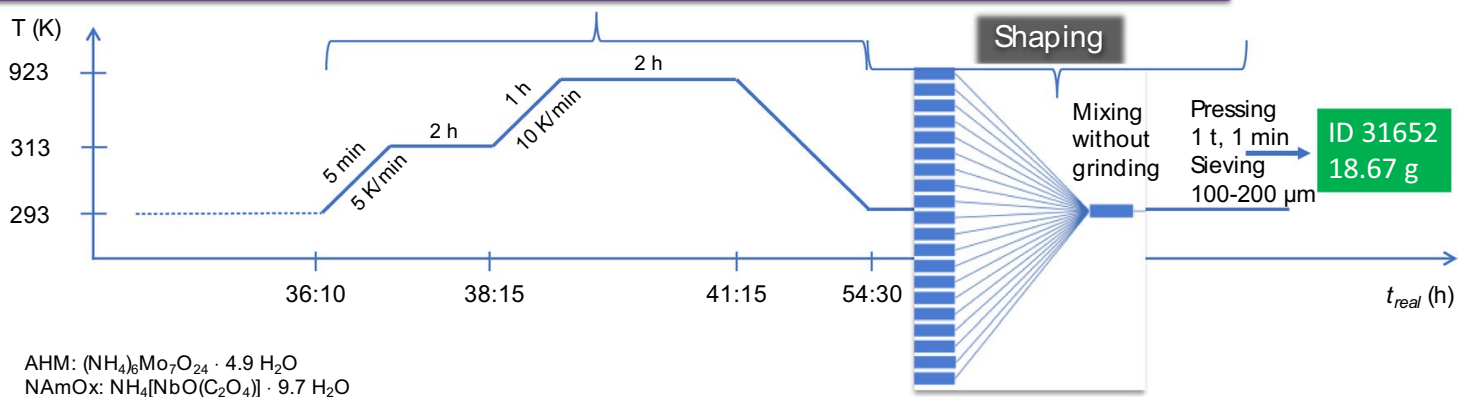

Fig. 7 Schematic illustration of the synthesis of a polycrystalline mixed MoVTeNb oxide with M1 crystal structure (ICSD 55097)

The reproducibility of the synthesis and differences before and after catalysis were carefully tested in the present work by using standard characterization techniques including structural analysis by powder X-ray diffraction, determination of the specific surface area by nitrogen adsorption at liquid nitrogen temperature, chemical analysis by X-ray fluorescence and laboratory X-ray photoelectron spectroscopy complemented by Raman, UV/Vis, and FTIR spectra (Fig. 5). The CO oxidation activity was measured for all fresh catalysts in two different feeds. Stabilities and redox properties of the fresh catalysts were analyzed by thermal analysis and by temperature-programmed reduction/oxidation cycles. In the course of the project, it turned out that it is useful to perform a rapid activation procedure at high temperature and high conversion in the feed of the catalytic reaction before starting the catalytic test or performing any advanced characterization.

Figure 8 illustrates that in some cases even the bulk composition of a catalyst is changed due to the harsh conditions in the rapid activation phase. In the present example, the vanadium content of the MoV oxide catalyst is increased perhaps due to the loss of volatile molybdenum hydroxide. The surface composition of MoV oxide as measured by laboratory XPS differs slightly from the bulk composition, however, major changes occur under operation. The operando synchrotron-based near ambient pressure XPS measurements, which are even more surface-sensitive compared to laboratory XPS, reveal an immense enrichment of vanadium on the surface confirming the dynamics of oxidation
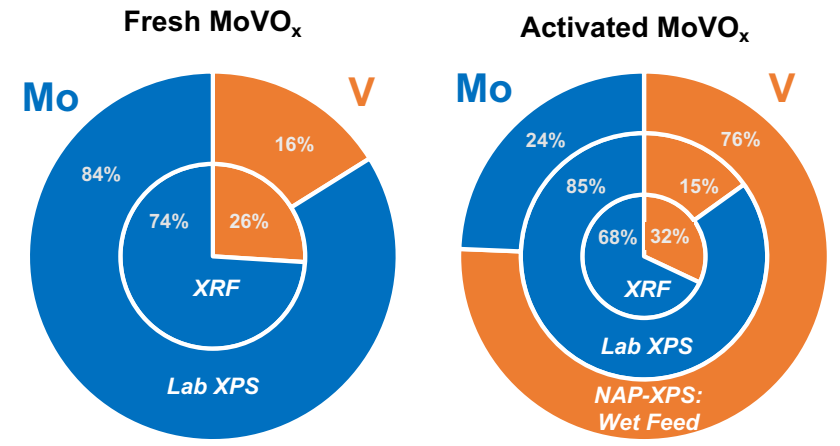

Fig. 8 Chemical analysis of a $\mathrm{MoVO}_{\mathrm{x}}$ catalyst after preparation (left, catalyst ID 31012) and after rapid activation in wet feed at high conversion (see handbook in the Supporting Information for details, right, catalyst ID 31804); The bulk analysis was performed by X-ray fluorescence (XRF); near surface analysis was performed by laboratory XPS; The surface composition under operation was determined by NAP-XPS

catalysts under working conditions. Advanced characterization, such as the determination of the heat of adsorption of reactants and intermediates by microcalorimetry and flow calorimetry, the measurement of work functions, valence band, and X-ray absorption spectra by synchrotron-based photoelectron spectroscopy, and the analysis of the conductivity in presence of different gas atmospheres, which is also implemented in the present project, was therefore performed using mainly the activated catalysts (Fig. 5). 


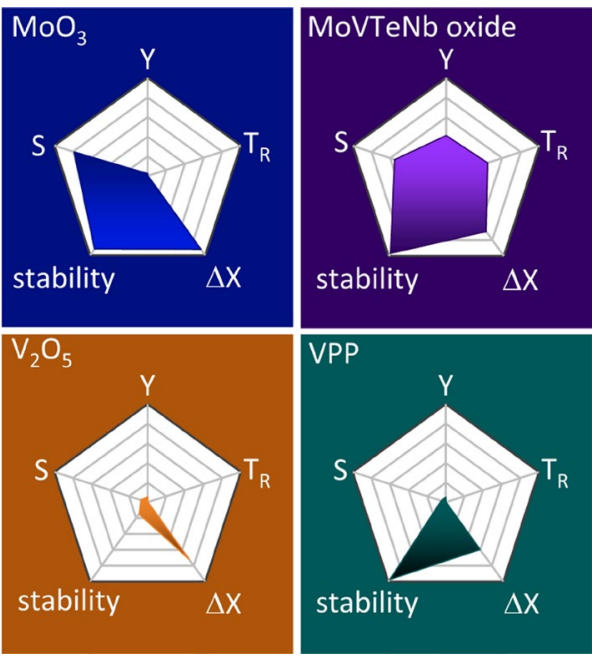

Fig. 9 Comparison of four catalysts in the oxidation of propane according to the procedure described in the handbook (Supporting information) based on values at the corners of the pentagram normalized between 0 (center) and 1(edge); $Y$ denotes the yield of acrylic acid, $T_{R}$ is the temperature (normalized between 225 and $450{ }^{\circ} \mathrm{C}$ ) at which $30 \%$ conversion of propane is reached, $\Delta X$ describes the deviation of the conversion plotted as a function of contact time from linearity, "stability" describes the difference in activity between an early and a late reference measurement in the testing procedure, and $S$ is the selectivity to the desired oxidation product at a propane conversion of $30 \%$ or at the highest reaction temperature; Formulas used to calculated the values in the radar plots are provided in the handbook, see Supporting Information

In the analysis of the catalytic data we develop modes of data representation and data reduction as illustrated in Fig. 9. The results of testing by applying a broad parameter field (see handbook in the Supporting Information) are condensed in the pentagrams shown in Fig. 9 as an example for four different catalysts. The performance is compared in terms of the yield to the desired oxidation product, activity, selectivity to value-added products, stability under extreme conditions, and quality of the measurements with respect to the minimization of transport phenomena. The size of the colored area allows a direct reading of the overall performance and a ranking of the catalysts. In the ongoing project it is also being examined how catalytic test reactors must be designed to allow measurements according to standardized operation procedures, perform transparent data analysis, and guarantee the documentation of all metadata. This project is still in progress and the results will be published in the near future.

\section{Conclusions and Outlook}

Scientific advance in catalysis needs integration of experiment and theory. However, only the smallest part of existing experimental catalysis-related data meets the criteria for data science and re-usability. Frequently, the dynamics of the catalysts are not taken into account. Furthermore, the necessity to apply a broad parameter field in catalyst testing receives not sufficient consideration.

The definition of standards and best practice operation procedures is necessary to enable quality control and to guarantee the measurement of reliable and sufficient diverse data sets that are compatible with up to date data analytics. The purpose of the present essay is to contribute to the scientific discussion about quality standards in catalysis research.

We emphasize that experimental kinetic data must be linked to all metadata including the workflow of the entire experiment. This also applies to details of catalyst synthesis and activation. We propose the implementation of handbooks for various types of catalysts and catalytic reactions, and we are keen on discussing quality standards within the community.

The starting platforms for discussions could be workshops at national and international conferences, in which handbook concepts for important classes of reactions are presented followed by discussions and refinements in weblogs within the community. Finally, publishers and funding agencies will be involved in establishing rigorous measurement protocols.

New trends in the methods of storing catalysis data beyond publications in classical journals will also contribute to a change in the paradigm and will help to improve the public access to standardized data, see for example the advancements for computationally generated data in material sciences [123], surface reactions [124], but also experimental data [125].

Successful integration and improved general awareness of the level of complexity involved in catalytic reactions will advance the field and will lay the foundation for disruptive concepts and technologies in heterogeneous catalysis. This will provide solutions to ensure sustainability in the chemical industry rendering the society's future energy and materials supply possible.

Acknowledgements This work was conducted in the framework of the BasCat collaboration between BASF SE, Technical University Berlin, Fritz-Haber-Institut der Max-Planck-Gesellschaft, and the clusters of excellence "Unified Concepts in Catalysis"/"Unifying Systems in Catalysis" (UniCat https://www.unicat.tu-berlin.de/UniSysCat https ://www.unisyscat.de). We thank the members of the technical staff at BasCat, in particular Jan Meißner, and those members of the Department of Inorganic Chemistry at the Fritz-Haber-Institut who were not directly involved in the project for their support. The Helmholtz-Zentrum Berlin is acknowledged for providing beamtime (proposal number 191-08444-IN/CO) and for the continuous support of the ambient pressure XPS activities of the MPG at BESSY II.

Author contributions The article was written by AT. The other authors are included in alphabetical order, because the article describes the collaboration project "Clean Data in Catalysis" between the Departments 
of Inorganic Chemistry, the NOMAD Laboratory of the Fritz-HaberInstitut der Max-Planck-Gesellschaft in Berlin, and the UniCat-BASF Joint Lab at the Technical University Berlin, in which all co-authors are involved. The co-authors contributed to the conceptual discussion in the project and/or by generation of data shown in the article. LF, LMG, MS, and PT have written paragraphs on AI and data analysis.

Funding Open Access funding enabled and organized by Projekt DEAL. Clusters of Excellence "Unified Concepts in Catalysis" /"Unifying Systems in Catalysis" (UniCat https://www.unicat.tu-berlin.de / UniSysCat https://www.unisyscat.de).

Data Availability In-house database of the Department of Inorganic Chemistry at the Fritz Haber Institute of the Max Planck Society https ://www.fhi-berlin.mpg.de/acnew/department/pages/database.html.

Code availability Not applicable.

\section{Compliance with Ethical Standards}

Conflict of interest There are no conflict of interest.

Open Access This article is licensed under a Creative Commons Attribution 4.0 International License, which permits use, sharing, adaptation, distribution and reproduction in any medium or format, as long as you give appropriate credit to the original author(s) and the source, provide a link to the Creative Commons licence, and indicate if changes were made. The images or other third party material in this article are included in the article's Creative Commons licence, unless indicated otherwise in a credit line to the material. If material is not included in the article's Creative Commons licence and your intended use is not permitted by statutory regulation or exceeds the permitted use, you will need to obtain permission directly from the copyright holder. To view a copy of this licence, visit http://creativecommons.org/licenses/by/4.0/.

\section{References}

1. Schlögl R (2015) Heterogeneous catalysis. Angew Chem Int Ed 54(11):3465-3520. https://doi.org/10.1002/anie.201410738

2. Nørskov JK, Weckhuysen B, Centi G, Chorkendorff I, Schlögl R, Marin G, Grimaud A, Rossmeisl J, Strasser P, Koper M, Roldan B, Behrens M, Bowker M, Hutchings G, Bordiga S, Lercher J, Nilsson A, Stephens I, Cantat T, Leitner W, DeBeer S, Groot Hd, Jacobsen KW, Scheffler M, Moses PG, Schreiber M, Gazzani M, Mazzotti M, Iaquaniello G, Schouten KJ, Growitsch C, Schmidt C (2019) Research needs towards sustainable production of fuels and chemicals. https://www.energy-x.eu/wp-content/ uploads/2019/10/Energy-X-Research-needs-report.pdf. Accessed 14 Aug 2020

3. Schlögl R (2016) Selective oxidation: from a still immature technology to the roots of catalysis science. Top Catal 59(17):14611476. https://doi.org/10.1007/s11244-016-0684-x

4. Kube P, Frank B, Schlögl R, Trunschke A (2017) Isotope studies in oxidation of propane over vanadium oxide. ChemCatChem 9:3446-3455. https://doi.org/10.1002/cctc. 201700847

5. Védrine J (2017) Heterogeneous catalysis on metal oxides. Catalysts $7(11): 341$

6. Grant JT, Venegas JM, McDermott WP, Hermans I (2018) Aerobic oxidations of light alkanes over solid metal oxide catalysts. Chem Rev 118(5):2769-2815. https://doi.org/10.1021/acs.chemr ev.7b00236
7. Schwach P, Pan X, Bao X (2017) Direct conversion of methane to value-added chemicals over heterogeneous catalysts: challenges and prospects. Chem Rev 117(13):8497-8520. https:// doi.org/10.1021/acs.chemrev.6b00715

8. Grasselli RK (2005) Selectivity issues in (amm)oxidation catalysis. Catal Today 99(1-2):23-31

9. Filot IAW, Broos RJP, van Rijn JPM, van Heugten GJHA, van Santen RA, Hensen EJM (2015) First-principles-based microkinetics simulations of synthesis gas conversion on a stepped rhodium surface. ACS Catal 5(9):5453-5467. https://doi. org/10.1021/acscatal.5b01391

10. Medford A, Lausche A, Abild-Pedersen F, Temel B, Schjødt N, Nørskov J, Studt F (2014) Activity and selectivity trends in synthesis gas conversion to higher alcohols. Top Catal 57(1-4):135142. https://doi.org/10.1007/s11244-013-0169-0

11. Luk HT, Mondelli C, Ferre DC, Stewart JA, Perez-Ramirez J (2017) Status and prospects in higher alcohols synthesis from syngas. Chem Soc Rev 46(5):1358-1426. https://doi. org/10.1039/C6CS00324A

12. Ravi M, Ranocchiari M, van Bokhoven JA (2017) The direct catalytic oxidation of methane to methanol - a critical assessment. Angew Chem Int Ed 56(52):16464-16483. https://doi. org/10.1002/anie.201702550

13. Grasselli RK, Burrington JD (2008) Oxidation of low-molecularweight hydrocarbons. In: Ertl G, Knözinger H, Weitkamp J (eds) Handbook of heterogeneous catalysis, 2nd edn. Wiley, Hoboken, pp 3479-3489

14. Trunschke A (2011) Propane selective oxidation to acrylic acid. In: Hess C, Schlögl R (eds) Nanostructured catalysts: selective oxidation reactions, 1st edn. RSC Nanoscience \& Nanotechnology, Cambridge, pp 56-95

15. Eichelbaum M, Glaum R, Hävecker M, Wittich K, Heine C, Schwarz H, Dobner C-K, Welker-Nieuwoudt C, Trunschke A, Schlögl R (2013) Towards physical descriptors of active and selective catalysts for the oxidation of n-butane to maleic anhydride. ChemCatChem 5(8):2318-2329. https://doi.org/10.1002/ cctc. 201200953

16. Getsoian AB, Zhai Z, Bell AT (2014) Band-gap energy as a descriptor of catalytic activity for propene oxidation over mixed metal oxide catalysts. J Am Chem Soc 136(39):13684-13697. https://doi.org/10.1021/ja5051555

17. De Moor BA, Reyniers M-F, Gobin OC, Lercher JA, Marin GB (2011) Adsorption of C2-C8 n-alkanes in zeolites. J Phys Chem C 115(4):1204-1219. https://doi.org/10.1021/jp106536m

18. Capdevila-Cortada M, Vilé G, Teschner D, Pérez-Ramírez J, López N (2016) Reactivity descriptors for ceria in catalysis. Appl Catal B 197:299-312. https://doi.org/10.1016/j.apcat b.2016.02.035

19. Grasselli RK (2002) Fundamental principles of selective heterogeneous oxidation catalysis. Top Catal 21(1-3):79-88

20. Kitchin JR (2018) Machine learning in catalysis. Nat Catal 1(4):230-232. https://doi.org/10.1038/s41929-018-0056-y

21. Andersen M, Levchenko SV, Scheffler M, Reuter K (2019) Beyond scaling relations for the description of catalytic materials. ACS Catal 9(4):2752-2759. https://doi.org/10.1021/acsca tal.8b04478

22. Ghiringhelli LM, Vybiral J, Levchenko SV, Draxl C, Scheffler M (2015) Big data of materials science: critical role of the descriptor. Phys Rev Lett 114(10):105503

23. Takahashi K, Takahashi L, Miyazato I, Fujima J, Tanaka Y, Uno T, Satoh H, Ohno K, Nishida M, Hirai K, Ohyama J, Nguyen TN, Nishimura S, Taniike T (2019) The rise of catalyst informatics: towards catalyst genomics. ChemCatChem 11(4):1146-1152. https://doi.org/10.1002/cctc.201801956

24. Medford AJ, Kunz MR, Ewing SM, Borders T, Fushimi R (2018) Extracting knowledge from data through catalysis informatics. 
ACS Catal 8(8):7403-7429. https://doi.org/10.1021/acsca tal.8b01708

25. Li Z, Wang S, Xin H (2018) Toward artificial intelligence in catalysis. Nat Catal 1(9):641-642. https://doi.org/10.1038/s4192 9-018-0150-1

26. Goldsmith BR, Esterhuizen J, Liu J-X, Bartel CJ, Sutton C (2018) Machine learning for heterogeneous catalyst design and discovery. AIChE J 64(7):2311-2323. https://doi.org/10.1002/ aic. 16198

27. Ulissi ZW, Medford AJ, Bligaard T, Nørskov JK (2017) To address surface reaction network complexity using scaling relations machine learning and DFT calculations. Nat Commun 8:14621. https://doi.org/10.1038/ncomms 14621

28. Schlexer Lamoureux P, Winther KT, Garrido Torres JA, Streibel V, Zhao M, Bajdich M, Abild-Pedersen F, Bligaard T (2019) Machine learning for computational heterogeneous catalysis. ChemCatChem 11(16):3581-3601. https://doi.org/10.1002/ cctc. 201900595

29. Williams T, McCullough K, Lauterbach JA (2020) Enabling catalyst discovery through machine learning and high-throughput experimentation. Chem Mater 32(1):157-165. https://doi. org/10.1021/acs.chemmater.9b03043

30. Palkovits R, Palkovits S (2019) Using artificial intelligence to forecast water oxidation catalysts. ACS Catal 9(9):8383-8387. https://doi.org/10.1021/acscatal.9b01985

31. Smith A, Keane A, Dumesic JA, Huber GW, Zavala VM (2020) A machine learning framework for the analysis and prediction of catalytic activity from experimental data. Appl Catal B 263:118257. https://doi.org/10.1016/j.apcatb.2019.118257

32. Suram SK, Haber JA, Jin J, Gregoire JM (2015) Generating information-rich high-throughput experimental materials genomes using functional clustering via multitree genetic programming and information theory. ACS Comb Sci 17(4):224-233. https:// doi.org/10.1021/co5001579

33. Berger RJ, Stitt EH, Marin GB, Kapteijn F, Moulijn JA (2001) Eurokin. Chemical reaction kinetics in practice. CATTECH 5(1):36-60. https://doi.org/10.1023/A:1011928218694

34. Chorkendorff I, Niemantsverdriet JW (2003) Solid catalysts. In: Chorkendorff I, Niemantsverdriet JW (eds) Concepts of modern catalysis and kinetics. Wiley, Weinheim, pp 167-214

35. Birtill JJ (2007) Measurement and modeling of the kinetics of catalyst decay in fixed beds: the eurokin survey. Ind Eng Chem Res 46(8):2392-2398. https://doi.org/10.1021/ie060590v

36. Macht J, Carr RT, Iglesia E (2009) Functional assessment of the strength of solid acid catalysts. J Catal 264(1):54-66

37. Marcu A, Toth G, Kundu S, Colmenares LC, Behm RJ (2012) Ex situ testing method to characterize cathode catalysts degradation under simulated start-up/shut-down conditions-a contribution to polymer electrolyte membrane fuel cell benchmarking. J Power Sources 215:266-273. https://doi.org/10.1016/j.jpows our.2012.05.010

38. Hattrick-Simpers J, Wen C, Lauterbach J (2015) The materials super highway: integrating high-throughput experimentation into mapping the catalysis materials genome. Catal Lett 145(1):290 298. https://doi.org/10.1007/s10562-014-1442-y

39. Tsakoumis NE, York APE, Chen D, Rønning M (2015) Catalyst characterisation techniques and reaction cells operating at realistic conditions; towards acquisition of kinetically relevant information. Catal Sci Technol 5(11):4859-4883. https://doi. org/10.1039/C5CY00269A

40. Bligaard T, Bullock RM, Campbell CT, Chen JG, Gates BC, Gorte RJ, Jones CW, Jones WD, Kitchin JR, Scott SL (2016) Toward benchmarking in catalysis science: best practices, challenges, and opportunities. ACS Catal 6(4):2590-2602. https:// doi.org/10.1021/acscatal.6b00183
41. Lange J-P (2016) Catalysis for biorefineries-performance criteria for industrial operation. Catal Sci Technol 6(13):4759-4767. https://doi.org/10.1039/C6CY00431H

42. Moniri S, Van Cleve T, Linic S (2017) Pitfalls and best practices in measurements of the electrochemical surface area of platinumbased nanostructured electro-catalysts. J Catal 345:1-10. https:// doi.org/10.1016/j.jcat.2016.11.018

43. Spanos I, Auer AA, Neugebauer S, Deng X, Tüysüz H, Schlögl $R$ (2017) Standardized benchmarking of water splitting catalysts in a combined electrochemical flow cell/inductively coupled plasma-optical emission spectrometry (ICP-OES) setup. ACS Catal 7(6):3768-3778. https://doi.org/10.1021/acscatal.7b00632

44. Andersen SZ, Čolić V, Yang S, Schwalbe JA, Nielander AC, McEnaney JM, Enemark-Rasmussen K, Baker JG, Singh AR, Rohr BA, Statt MJ, Blair SJ, Mezzavilla S, Kibsgaard J, Vesborg PCK, Cargnello M, Bent SF, Jaramillo TF, Stephens IEL, Nørskov JK, Chorkendorff I (2019) A rigorous electrochemical ammonia synthesis protocol with quantitative isotope measurements. Nature 570(7762):504-508. https://doi.org/10.1038/s4158 6-019-1260-x

45. Kramm UI, Marschall R, Rose M (2019) Pitfalls in heterogeneous thermal, electro- and photocatalysis. ChemCatChem 11(11):2563-2574. https://doi.org/10.1002/cctc.201900137

46. Suryanto BHR, Du H-L, Wang D, Chen J, Simonov AN, MacFarlane DR (2019) Challenges and prospects in the catalysis of electroreduction of nitrogen to ammonia. Nat Catal 2(4):290-296. https://doi.org/10.1038/s41929-019-0252-4

47. Chen JG, Jones CW, Linic S, Stamenkovic VR (2017) Best practices in pursuit of topics in heterogeneous electrocatalysis. ACS Catal 7(9):6392-6393. https://doi.org/10.1021/acscatal.7b02839

48. Schüth F, Ward MD, Buriak JM (2018) Common pitfalls of catalysis manuscripts submitted to chemistry of materials. Chem Mater 30(11):3599-3600. https://doi.org/10.1021/acs.chemm ater. $8 \mathrm{~b} 01831$

49. Scott SL (2018) A matter of life(time) and death. ACS Catal 8(9):8597-8599. https://doi.org/10.1021/acscatal.8b03199

50. Of best practice in catalysis (2020). Nat Catal 3(6):471-472. https://doi.org/10.1038/s41929-020-0480-7

51. Alberi K, Nardelli MB, Zakutayev A, Mitas L, Curtarolo S, Jain A, Fornari M, Marzari N, Takeuchi I, Green ML, Kanatzidis M, Toney MF, Butenko S, Meredig B, Lany S, Kattner U, Davydov A, Toberer ES, Stevanovic V, Walsh A, Park N-G, Aspuru-Guzik A, Tabor DP, Nelson J, Murphy J, Setlur A, Gregoire J, Li H, Xiao R, Ludwig A, Martin LW, Rappe AM, Wei S-H, Perkins J (2018) The 2019 materials by design roadmap. J Phys D Appl Phys 52(1):013001. https://doi.org/10.1088/1361-6463/aad926

52. Pfeif EA, Kroenlein K (2016) Perspective: data infrastructure for high throughput materials discovery. APL Mater. 4(5):053203. https://doi.org/10.1063/1.4942634

53. Allmann R, Hinek R (2007) The introduction of structure types into the inorganic crystal structure database ICSD. Acta Crystallogr Sect A 63(5):412-417. https://doi.org/10.1107/S010876730 7038081

54. Trunschke A (2013) Synthesis of solid catalysts. In: Schlögl R (ed) Chemical energy storage. Walter de Gruyter GmbH, Berlin/ Boston, pp 277-301

55. Nørskov JK, Bligaard T, Rossmeisl J, Christensen CH (2009) Towards the computational design of solid catalysts. Nat Chem 1(1):37-46. https://doi.org/10.1038/nchem.121

56. Bronsted JN (1928) Acid and basic catalysis. Chem Rev 5(3):231-338. https://doi.org/10.1021/cr60019a001

57. Evans MG, Polanyi M (1938) Inertia and driving force of chemical reactions. Trans Faraday Soc 34:11-24. https://doi. org/10.1039/TF9383400011 
58. Nørskov JK, Bligaard T, Logadottir A, Bahn S, Hansen LB, Bollinger M, Bengaard H, Hammer B, Sljivancanin Z, Mavrikakis M, Xu Y, Dahl S, Jacobsen CJH (2002) Universality in heterogeneous catalysis. J Catal 209(2):275-278. https://doi.org/10.1006/ jcat.2002.3615

59. Sabatier P (1911) Hydrogénations et déshydrogénations par catalyse. Ber Dtsch Chem Ges 44(3):1984-2001. https://doi. org/10.1002/cber.19110440303

60. Medford AJ, Vojvodic A, Hummelshøj JS, Voss J, Abild-Pedersen F, Studt F, Bligaard T, Nilsson A, Nørskov JK (2015) From the Sabatier principle to a predictive theory of transitionmetal heterogeneous catalysis. J Catal 328:36-42. https://doi. org/10.1016/j.jcat.2014.12.033

61. Fu G, Xu X, Lu X, Wan HL (2005) Mechanisms of initial propane activation on molybdenum oxides: a density functional theory study. J Phys Chem B 109(13):6416-6421

62. Fu G, Chen Z-N, Xu X, Wan H-L (2008) Understanding the reactivity of the tetrahedrally coordinated high-valence $\mathrm{d} 0$ transition metal oxides toward the $\mathrm{C}-\mathrm{H}$ bond activation of alkanes: a cluster model study. J Phys Chem A 112(4):717-721. https://doi. org/10.1021/jp709651n

63. Rozanska X, Fortrie R, Sauer J (2007) Oxidative dehydrogenation of propane by monomeric vanadium oxide sites on silica support. J Phys Chem C 111(16):6041-6050

64. Rozanska X, Fortrie R, Sauer J (2014) Size-dependent catalytic activity of supported vanadium oxide species: oxidative dehydrogenation of propane. J Am Chem Soc 136(21):7751-7761. https ://doi.org/10.1021/ja503130z

65. Latimer AA, Kulkarni AR, Aljama H, Montoya JH, Yoo JS, Tsai C, Abild-Pedersen F, Studt F, Nørskov JK (2017) Understanding trends in $\mathrm{C}-\mathrm{H}$ bond activation in heterogeneous catalysis. Nat Mater 16(2):225-229. https://doi.org/10.1038/nmat4760

66. Deshlahra P, Iglesia E (2016) Reactivity and selectivity descriptors for the activation of $\mathrm{C}-\mathrm{H}$ bonds in hydrocarbons and oxygenates on metal oxides. J Phys Chem C 120(30):16741-16760. https://doi.org/10.1021/acs.jpcc.6b04604

67. Chrétien S, Metiu H (2006) Density functional study of the CO oxidation on a doped rutile $\mathrm{TiO} 2(110)$ : effect of ionic $\mathrm{Au}$ in catalysis. Catal Lett 107(3):143-147. https://doi.org/10.1007/ s10562-005-0014-6

68. McFarland EW, Metiu H (2013) Catalysis by doped oxides. Chem Rev 113(6):4391-4427. https://doi.org/10.1021/cr300418s

69. Hinuma Y, Toyao T, Kamachi T, Maeno Z, Takakusagi S, Furukawa S, Takigawa I, Shimizu K-i (2018) Density functional theory calculations of oxygen vacancy formation and subsequent molecular adsorption on oxide surfaces. J Phys Chem C 122(51):29435-29444. https://doi.org/10.1021/acs.jpcc.8b11279

70. Boreskov GK (1966) Forms of oxygen bonds on the surface of oxidation catalysts. Discuss Faraday Soc 41:263-276. https://doi. org/10.1039/DF9664100263

71. Panov GI, Dubkov KA, Starokon EV (2006) Active oxygen in selective oxidation catalysis. Catal Today 117(1-3):148-155

72. Panov GI, Parfenov MV, Parmon VN (2015) The BrønstedEvans-Polanyi correlations in oxidation catalysis. Catal Rev 57(4):436-477. https://doi.org/10.1080/01614940.2015.1074487

73. Eichelbaum M, Hävecker M, Heine C, Karpov A, Dobner C-K, Rosowski F, Trunschke A, Schlögl R (2012) The intimate relationship between bulk electronic conductivity and selectivity in the catalytic oxidation of n-butane. Angew Chem Int Ed 51(25):6246-6250. https://doi.org/10.1002/anie.201201866

74. Wernbacher AM, Kube P, Hävecker M, Schlögl R, Trunschke A (2019) Electronic and dielectric properties of MoV-oxide (M1 phase) under alkane oxidation conditions. J Phys Chem C 123(21):13269-13282. https://doi.org/10.1021/acs.jpcc.9b01273

75. Avdeev VI, Bedilo AF (2016) Molecular mechanism of propane oxidative dehydrogenation on surface oxygen radical sites of VO x /TiO2 catalysts. Res Chem Intermed 42(6):5237-5252. https:// doi.org/10.1007/s11164-015-2355-0

76. Bielański A, Haber J (1979) Oxygen in catalysis on transition metal oxides. Catal Rev 19(1):1-41. https://doi. org/10.1080/03602457908065099

77. Vojvodic A, Calle-Vallejo F, Guo W, Wang S, Toftelund A, Studt F, Martínez JI, Shen J, Man IC, Rossmeisl J, Bligaard T, Nørskov JK, Abild-Pedersen F (2011) On the behavior of BrønstedEvans-Polanyi relations for transition metal oxides. J Chem Phys 134(24):244509. https://doi.org/10.1063/1.3602323

78. Lee Y-L, Kleis J, Rossmeisl J, Shao-Horn Y, Morgan D (2011) Prediction of solid oxide fuel cell cathode activity with firstprinciples descriptors. Energy Environ Sci 4(10):3966-3970. https://doi.org/10.1039/C1EE02032C

79. Rossmeisl J, Qu ZW, Zhu H, Kroes GJ, Nørskov JK (2007) Electrolysis of water on oxide surfaces. J Electroanal Chem 607(1):83-89. https://doi.org/10.1016/j.jelechem.2006.11.008

80. Hong WT, Welsch RE, Shao-Horn Y (2016) Descriptors of oxygen-evolution activity for oxides: a statistical evaluation. J Phys Chem C 120(1):78-86. https://doi.org/10.1021/acs.jpcc.5b10071

81. Cheng X, Fabbri E, Yamashita Y, Castelli IE, Kim B, Uchida M, Haumont R, Puente-Orench I, Schmidt TJ (2018) Oxygen evolution reaction on Perovskites: a multieffect descriptor study combining experimental and theoretical methods. ACS Catal 8(10):9567-9578. https://doi.org/10.1021/acscatal.8b02022

82. Bruix A, Margraf JT, Andersen M, Reuter K (2019) First-principles-based multiscale modelling of heterogeneous catalysis. Nat Catal 2(8):659-670. https://doi.org/10.1038/s41929-019-0298-3

83. Khorshidi A, Violet J, Hashemi J, Peterson AA (2018) How strain can break the scaling relations of catalysis. Nat Catal 1(4):263-268. https://doi.org/10.1038/s41929-018-0054-0

84. Amakawa K, Sun L, Guo C, Hävecker M, Kube P, Wachs IE, Lwin S, Frenkel AI, Patlolla A, Hermann K, Schlögl R, Trunschke A (2013) How strain affects the reactivity of surface metal oxide catalysts. Angew Chem Int Ed 52(51):13553-13557. https ://doi.org/10.1002/anie.201306620

85. Gani TZH, Kulik HJ (2018) Understanding and breaking scaling relations in single-site catalysis: methane to methanol conversion by FeIV=O. ACS Catal 8(2):975-986. https://doi.org/10.1021/ acscatal.7b03597

86. Back S, Jung Y (2017) TiC- and TiN-supported single-atom catalysts for dramatic improvements in $\mathrm{CO} 2$ electrochemical reduction to CH4. ACS Energy Lett 2(5):969-975. https://doi. org/10.1021/acsenergylett.7b00152

87. Li H, Li Y, Koper MTM, Calle-Vallejo F (2014) Bond-making and breaking between carbon, nitrogen, and oxygen in electrocatalysis. J Am Chem Soc 136(44):15694-15701. https://doi. org $/ 10.1021 / \mathrm{ja} 508649 \mathrm{p}$

88. Huang X, Teschner D, Dimitrakopoulou M, Fedorov A, Frank B, Kraehnert R, Rosowski F, Kaiser H, Schunk S, Kuretschka C, Schlögl R, Willinger M, Trunschke A (2019) Atomic-scale observation of the metal-promoter interaction in Rh-based syngas upgrading catalysts. Angew Chem Int Ed 58(26):8709-8713. https://doi.org/10.1002/anie.201902750

89. Li X, Teschner D, Streibel V, Lunkenbein T, Masliuk L, Fu T, Wang Y, Jones T, Seitz F, Girgsdies F, Rosowski F, Schlögl R, Trunschke A (2019) How to control selectivity in alkane oxidation? Chem Sci 10(8):2429-2443. https://doi.org/10.1039/ C8SC04641G

90. Werny MJ, Wang Y, Girgsdies F, Schlögl R, Trunschke A (2020) Fluctuating storage of the active phase in a Mn-Na2WO4/SiO2 catalyst for the oxidative coupling of methane. Angew Chem Int Ed. https://doi.org/10.1002/anie.202004778

91. Arakawa H, Aresta M, Armor JN, Barteau MA, Beckman EJ, Bell AT, Bercaw JE, Creutz C, Dinjus E, Dixon DA, Domen K, DuBois DL, Eckert J, Fujita E, Gibson DH, Goddard WA, 
Goodman DW, Keller J, Kubas GJ, Kung HH, Lyons JE, Manzer LE, Marks TJ, Morokuma K, Nicholas KM, Periana R, Que L, Rostrup-Nielson J, Sachtler WMH, Schmidt LD, Sen A, Somorjai GA, Stair PC, Stults BR, Tumas W (2001) Catalysis research of relevance to carbon management: progress, challenges, and opportunities. Chem Rev 101(4):953-996. https:// doi.org/10.1021/cr000018s

92. Masliuk L, Swoboda M, Algara-Siller G, Schlögl R, Lunkenbein T (2018) A quasi in situ TEM grid reactor for decoupling catalytic gas phase reactions and analysis. Ultramicroscopy 195:121-128. https://doi.org/10.1016/j.ultramic.2018.09.001

93. Masliuk L, Heggen M, Noack J, Girgsdies F, Trunschke A, Hermann KE, Willinger MG, Schlögl R, Lunkenbein T (2017) Structural complexity in heterogeneous catalysis: cataloging local nanostructures. J Phys Chem C 121(43):24093-24103. https:// doi.org/10.1021/acs.jpcc.7b08333

94. Mars P, van Krevelen DW (1954) Oxidations carried out by means of vanadium oxide catalysts. Chem Eng Sci 3:41-59. https ://doi.org/10.1016/S0009-2509(54)80005-4

95. Hävecker M, Wrabetz S, Kröhnert J, Csepei L-I, Naumann d'Alnoncourt R, Kolenko YV, Girgsdies F, Schlögl R, Trunschke A (2012) Surface chemistry of phase-pure M1 MoVTeNb oxide during operation in selective oxidation of propane to acrylic acid. J Catal 285(1):48-60. https://doi.org/10.1016/j.jcat.2011.09.012

96. Eichelbaum M, Hävecker M, Heine C, Wernbacher AM, Rosowski F, Trunschke A, Schlögl R (2015) The electronic factor in alkane oxidation catalysis. Angew Chem Int Ed 54(10):29222926. https://doi.org/10.1002/anie.201410632

97. Ouyang R, Curtarolo S, Ahmetcik E, Scheffler M, Ghiringhelli LM (2018) SISSO: a compressed-sensing method for identifying the best low-dimensional descriptor in an immensity of offered candidates. Phys Rev Mater 2(8):083802. https://doi.org/10.1103/ PhysRevMaterials.2.083802

98. Wilkinson SK, Simmons MJH, Stitt EH, Baucherel X, Watson MJ (2013) A novel approach to understanding and modelling performance evolution of catalysts during their initial operation under reaction conditions - case study of vanadium phosphorus oxides for n-butane selective oxidation. J Catal 299:249-260. https://doi. org/10.1016/j.jcat.2012.11.027

99. Föttinger K, Rupprechter G (2014) In situ spectroscopy of complex surface reactions on supported $\mathrm{Pd}-\mathrm{Zn}, \mathrm{Pd}-\mathrm{Ga}$, and $\mathrm{Pd}(\mathrm{Pt})-$ Cu nanoparticles. Acc Chem Res 47(10):3071-3079. https://doi. org/10.1021/ar500220v

100. Teschner D, Borsodi J, Wootsch A, Révay Z, Hävecker M, KnopGericke A, Jackson SD, Schlögl R (2008) The roles of subsurface carbon and hydrogen in palladium-catalyzed alkyne hydrogenation. Science 320(5872):86-89. https://doi.org/10.1126/science. 1155200

101. Hutchings GJ (2009) Heterogeneous catalysts-discovery and design. J Mater Chem 19(9):1222-1235

102. Kolen'ko YV, Zhang W, d'Alnoncourt RN, Girgsdies F, Hansen TW, Wolfram T, Schlögl R, Trunschke A (2011) Synthesis of MoVTeNb oxide catalysts with tunable particle dimensions. ChemCatChem 3(10):1597-1606. https://doi.org/10.1002/cctc.20110 0089

103. Körting E, Baerns M (1990) Die Anwendung von Expertensystemen zur Katalysator-Entwicklung. Chem Ing Tec 62(5):365-372. https://doi.org/10.1002/cite.330620504

104. Körting E, Baerns M (1993) ESYCAD — an expert system for catalyst design. In: Doyama M, Kihara J, Tanaka M, Yamamoto R (eds) Computer aided innovation of new materials II. Elsevier, Oxford, pp 1107-1110

105. Dumesic JA, Trevino AA, Milligan BA, Greppi LA, Balse VR, Sarnowski KT, Beall CE, Kataoka T, Rudd DF (1987) A kinetic modeling approach to the design of catalysts: formulation of a catalyst design advisory program. Ind Eng Chem Res 26(7):1399-1407. https://doi.org/10.1021/ie00067a022
106. Bond CG, Wells BP (1985) Characterization of the standard platinum/silica catalyst europt-1 philosophy and achievement. Appl Catal 18(2):221-224. https://doi.org/10.1016/S0166 -9834(00)84001-4

107. Klanner C, Farrusseng D, Baumes L, Lengliz M, Mirodatos C, Schüth F (2004) The development of descriptors for solids: teaching "catalytic intuition" to a computer. Angew Chem Int Ed 43(40):5347-5349. https://doi.org/10.1002/anie.200460731

108. Farrusseng D (2008) High-throughput heterogeneous catalysis. Surf Sci Rep 63(11):487-513. https://doi.org/10.1016/j.surfr ep.2008.09.001

109. Senkan S (2001) Combinatorial heterogeneous catalysis-a new path in an old field. Angew Chem Int Ed 40(2):312-329. https ://doi.org/10.1002/1521-3773(20010119)40:2<312:aid-anie3 $12>3.0 . \mathrm{co} ; 2-\mathrm{i}$

110. Corma A, Serra JM, Serna P, Moliner M (2005) Integrating highthroughput characterization into combinatorial heterogeneous catalysis: unsupervised construction of quantitative structure/ property relationship models. J Catal 232(2):335-341. https://doi. org/10.1016/j.jcat.2005.03.019

111. Clerc F, Lengliz M, Farrusseng D, Mirodatos C, Pereira SRM, Rakotomalala R (2005) Library design using genetic algorithms for catalyst discovery and optimization. Rev Sci Instrum 76(6):062208. https://doi.org/10.1063/1.1906086

112. Tompos A, Sanchez-Sanchez M, Végvári L, Szijjártó GP, Margitfalvi JL, Trunschke A, Schlögl R, Wanninger K, Mestl G (2019) Combinatorial optimization and synthesis of multiple promoted MoVNbTe catalysts for oxidation of propane to acrylic acid. Catal Today. https://doi.org/10.1016/j.cattod.2019.03.047

113. Zavyalova U, Holena M, Schlögl R, Baerns M (2011) Statistical analysis of past catalytic data on oxidative methane coupling for new insights into the composition of high-performance catalysts. ChemCatChem 3(12):1935-1947. https://doi.org/10.1002/ cctc. 201100186

114. Takahashi K, Miyazato I, Nishimura S, Ohyama J (2018) Unveiling hidden catalysts for the oxidative coupling of methane based on combining machine learning with literature data. ChemCatChem 10(15):3223-3228. https://doi.org/10.1002/cctc.201800310

115. Nguyen TN, Nhat TTP, Takimoto K, Thakur A, Nishimura S, Ohyama J, Miyazato I, Takahashi L, Fujima J, Takahashi K, Taniike T (2020) High-throughput experimentation and catalyst informatics for oxidative coupling of methane. ACS Catal 10(2):921-932. https ://doi.org/10.1021/acscatal.9b04293

116. Volpe AF, Lugmair CG (2020) High-throughput heterogeneous catalyst research, development, scale-up, and production support. In: Wandelt K (ed) Surface and interface science. Wiley, Weinheim, pp 611-661

117. Maier WF (2019) Early years of high-throughput experimentation and combinatorial approaches in catalysis and materials science. ACS Comb Sci 21(6):437-444. https://doi.org/10.1021/acscombsci $.8 \mathrm{~b} 00189$

118. Schlögl R (1998) Combinatorial chemistry in heterogeneous catalysis: a new scientific approach or "the king's new clothes"? Angew Chem Int Ed 37(17):2333-2336. https://doi.org/10.1002/ (sici)1521-3773(19980918)37:17<2333:Aid-anie2333>3.0.Co;2-j

119. Wilkinson MD, Dumontier M, Aalbersberg IJ, Appleton G, Axton M, Baak A, Blomberg N, Boiten J-W, da Silva Santos LB, Bourne PE, Bouwman J, Brookes AJ, Clark T, Crosas M, Dillo I, Dumon O, Edmunds S, Evelo CT, Finkers R, Gonzalez-Beltran A, Gray AJG, Groth P, Goble C, Grethe JS, Heringa J, Hoen PAC, Hooft R, Kuhn T, Kok R, Kok J, Lusher SJ, Martone ME, Mons A, Packer AL, Persson B, Rocca-Serra P, Roos M, van Schaik R, Sansone S-A, Schultes E, Sengstag T, Slater T, Strawn G, Swertz MA, Thompson M, van der Lei J, van Mulligen E, Velterop J, Waagmeester A, Wittenburg P, Wolstencroft K, Zhao J, Mons B (2016) The FAIR guiding principles for scientific data management and 
stewardship. Sci Data 3(1):160018. https://doi.org/10.1038/sdata .2016 .18

120. Draxl C, Scheffler M (2018) NOMAD: the FAIR concept for big data-driven materials science. MRS Bull 43(9):676-682. https:// doi.org/10.1557/mrs.2018.208

121. Sanchez Sanchez M, Girgsdies F, Jastak M, Kube P, Schlögl R, Trunschke A (2012) Aiding the self-assembly of supramolecular polyoxometalates under hydrothermal conditions to give precursors of complex functional oxides. Angew Chem Int Ed 51(29):71947197. https://doi.org/10.1002/anie.201200746

122. Noack J, Rosowski F, Schlögl R, Trunschke A (2014) Speciation of molybdates under hydrothermal conditions. Z für Anorganische und Allgemeine Chem 640(14):2730-2736. https://doi. org/10.1002/zaac.201400439
123. Himanen L, Geurts A, Foster AS, Rinke P (2019) Data-driven materials science: status, challenges, and perspectives. Adv Sci 6(21):1900808. https://doi.org/10.1002/advs.201900808

124. Winther KT, Hoffmann MJ, Boes JR, Mamun O, Bajdich M, Bligaard T (2019) Catalysis-Huborg, an open electronic structure database for surface reactions. Sci Data 6(1):75. https://doi. org/10.1038/s41597-019-0081-y

125. Fujima J (2020) Catalyst Acquisition by Data Science (CADS). https://cads.eng.hokudai.ac.jp/. Accessed 14 Aug 2020

Publisher's Note Springer Nature remains neutral with regard to jurisdictional claims in published maps and institutional affiliations. 